\author{
Military Technical College \\ Kobry El-Kobbah, \\ Cairo, Egypt.
}

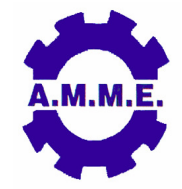

\title{
THE EFFECTS OF FIBERGLASS ON THE THERMAL INSULATION PROPERTIES OF INTUMESCENT COATING
}

\author{
F. Ahmad ${ }^{*}$ S. Ullah ${ }^{* *}$, N. Amir ${ }^{* * *}$ and N. S. Omar ${ }^{* * *}$
}

\begin{abstract}
The aim of this study is to investigate the influence of fibreglass addition into the basic intumescent coating formulation towards the enhancement of its thermal insulation properties. The intumescent coating were formulated from expandable graphite (EG), ammonium polyphosphate (APP), melamine (MEL), boric acid (BA), bisphenol A epoxy resin BE-188 (BPA), ACR Hardener $\mathrm{H}-2310$ polyamide amine and fiberglass (FG) of length $3.0 \mathrm{~mm}$. Eight different intumescent formulations were developed and the samples were tested for their fire performance by burning them at $450^{\circ} \mathrm{C}, 650^{\circ} \mathrm{C}$ and $850^{\circ} \mathrm{C}$ in the furnace for two hours. The effects of each fire test at different temperatures; low and high temperature were evaluated. Scanning Electron Microscope (SEM), X-Ray Diffraction technique (XRD) and Thermogravimetric Analysis (TGA) were conducted on the samples to study the char morphology, the crystalline material structure and chemical components and the thermal analysis of the coatings. The FG08 and FG07 formulations with 7.0 grams and 6.0 grams fiberglass provide better results with the enhanced thermal insulation properties of the coatings.
\end{abstract}

\section{KEY WORDS}

Component, intumescent coating, expandable graphite (EG), fiberglass.

Associate Professor, Dept. of Mech. Eng., Universiti Teknologi PETRONAS Malaysia.

** $\quad$ Ph.D., Dept. of Mech. Eng., Universiti Teknologi PETRONAS Malaysia.

*** Ph.D. student, Dept. of Mech. Eng., Universiti Teknologi PETRONAS Malaysia.

U*** Under graduate student, Dept. of Mech. Eng., Universiti Teknologi PETRONAS Malaysia. 


\section{INTRODUCTION}

The use of fire-retardant coatings is one of the easiest, oldest and most efficient ways to protect steel substrates against fire [1-2]. It is important to protect materials against fire in the construction and petrochemical industries to ensure safe evacuation of people from the building before the steel structures started to deteriorate quickly when exposed to temperature above $550^{\circ} \mathrm{C}$ [3]. The advantages of using intumescent coating is that it does not change the basic properties of the material (e.g. mechanical properties), easily processed and can be applied on several materials including metallic materials, polymers, textiles and wood $[1-2,4]$.

Intumescent is defined as the swelling of certain substances when they are heated [5-6]. Intumescent coatings form an expanded multicellular layer upon heating; namely char, which acts as thermal barrier that effectively protect the substrate against rapid increase of temperature and thereby maintaining the structural integrity of the building [7]. The physical structure of the charring layer plays a very important role in the performance of flame retardant. Formation of homogeneous char (high residue amount and good thickness) will ensure longer fire-endurance time and better performance of the flame retardant coating [7]. In recent years price efficiencies and improvements in technology have created a situation where intumescent coatings have come to dominate the structural fire protection market [89].

Several studies have demonstrated the use of filler and binder as reinforcing agent helps to increase the efficiency of the intumescent coatings in terms of providing longer protection to the structural steel [9-11]. Little studies focused on the effect of using fiberglass to increase the thermal insulation properties of the intumescent coatings. Fiberglass is used as reinforcement of the char strength [7, 12]. It helps to maintain the char integrity and provide a higher mechanical resistance of the charring element [12]. In terms of fire safety, fiberglass insulation is naturally noncombustible because it is made from sand and recycled glass [7-8].

The objective of this study was to investigate the thermal insulation properties of intumescent coating with varying amount of fibreglass added into the basic intumescent formulations. The optimum intumescent formulation with fibreglass, which provides the best thermal insulation properties against fire, was determined [7]. The study on the thermal insulation property of the intumescent coating will allow determination of exact temperature at which the charring of the mixture begins.

\section{MATERIALS AND PROCEDURE}

\section{Materials}

Ammonium poly phosphate (Exolit AP422) containing 20 percent phosphorus is used as the acid source was provided by Clariant (Malaysia) Sdn Bhd. Bisphenol A epoxy resin BE-188 (BPA) used as a binder with ACR Hardener $\mathrm{H}-2310$ polyamide amine also known as tetraethylene tetramine (TETA) were bought from Mc-Growth chemical Sdn Bhd. Malaysia. Structural steel A36M was supplied by TSA industries (Ipoh) Sdn. Bhd. Malaysia. Melamine used as a blowing agent and boric acid as a additive were purchased from Sigma-Aldrich (M) Sdn Bhd. Malaysia. Bhd. Graphite 
and short fiberglass (FG) of length $3.0 \mathrm{~mm}$ were purchased from Premier East West Malaysia Sdn. Bhd.

\section{Preparation of intumescent formulations}

Expandable graphite (EG) which was used as the carbon source was prepared by grinding and sieving the graphite powder into smaller particle size of $300 \mu \mathrm{m}$. A mixture of concentrated sulfuric acid (98\%, $37.5 \mathrm{~g}$ ), acetic acid (150.0 g), graphite powder $(75 \mathrm{~g})$ and potassium permanganate $(5.25 \mathrm{~g})$ was stirred at room temperature for 1 hour. The treated graphite was filtered, washed with distilled water until $\mathrm{pH}$ level closed to $6-7$ and dried at $100-110^{\circ} \mathrm{C}$ in the oven for $2-4$ hours.

Figure 1 shows the diagram of preparation of the coating. APP, MEL and boric acid are weighed and grinded into smaller particles to prevent the presence of bubbles inside the coating. BPA and ACR hardener are weighted and mixed together in the Ultra Turrax mixer until the mixture is homogenous. Next, expandable graphite and fiberglass are added into the mixture and stirred well until uniformly homogenous. The coatings were then applied on $3.5 \mathrm{~mm}$ thickness steel plates of dimensions $15 \mathrm{x}$ $50 \mathrm{~mm}^{2}$ and were left for curing at room temperature for 1-2 weeks. Table 1 shows the eight formulations of the intumescent coating.

\section{ANALYSIS AND CHARACTERIZATION}

\section{FIRE TEST}

The intumescent coating samples were burnt at three different temperatures; $450^{\circ} \mathrm{C}$, $650^{\circ} \mathrm{C}$ and $850^{\circ} \mathrm{C}$ for two hours in the furnace. The char expansion of sample was measured by using digital vernier caliper before and after fire test. The char morphology characteristics and microstructure of each sample were then determined using SEM and XRD.

\section{Thermal Insulation Test}

A Bunsen burner was used as a fire source to fire the intumescent samples according to the UL 94 standard. In every test, the coated steel was wired with a digital thermocouple for heating record. The temperature versus time measurements was taken using an electric data logger.

\section{Scanning Electron Microscopy (SEM)}

The charring layer and the morphological structures of the inside and outside coatings were observed and analyzed using Oxford Instrument SEM machine.

\section{Ray Diffraction Technique (XRD)}

The residual char composition of the intumescent coating was analyzed by XRD measurements were performed on a Diffractometer Bruker AXS D8 Advance using $\mathrm{Cu}$ Ka radiation and a nickel filter $(\mathrm{k}=0.150595 \mathrm{~nm})$ in the range $(10<2 \theta<90)$. 


\section{Thermogravimetric Analysis (TGA)}

The residual weight of intumescent coatings was analyzed using TGA. The thermogravimetric analysis of samples (approximately $10 \mathrm{mg}$ ) were carried out at $10^{\circ} \mathrm{C} /$ min under $\mathrm{N}_{2}$ over the whole range of temperature $\left(50^{\circ} \mathrm{C}-800^{\circ} \mathrm{C}\right)$ using PerkinElmer TGA Q50.

\section{RESULTS AND DISCUSSIONS}

\section{Fire Test Results}

\section{Fire test at $450^{\circ} \mathrm{C}$ and $650^{\circ} \mathrm{C}$}

The intumescent coating samples which showed the higher expansion are sample FG07 followed by samples FG06 and FG08. After the fire test, the coatings swelled and expanded into charring elements that protects the substrate steel from severe fire. The char have a very rough surface with major cracks and detachable towards the steel substrate. The microstructure of samples FG07 and FG08 were examined using SEM. Fig. 2 shows the graph of expansion ratio shown by each sample burnt

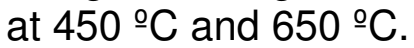

The samples which show the greatest amount of expansion were FG08 followed by FG07 coating. The char have a very rough surface with little cracks and sufficiently attached to the steel substrate.

\section{Fire test at $850 \circ \mathrm{C}$}

The results from the fire test conducted at temperature $850^{\circ} \mathrm{C}$ were the formation of white powder (ashes) from the coating. The formations of the ashes were due to the very high fire temperature of the furnace. Fig. 3 shows the burnt intumescent coating samples. Another research however, proved fiberglass reinforced intumescent coating adequately endured an-hour long, $800^{\circ} \mathrm{C}$ furnace fire test without turning into ashes [12].

\section{Thermal Insulation Test Results}

The thermal properties of the coating with fiberglass were compared to the thermal properties of the coating without fiberglass as in Fig. 4. The coating without fiberglass was observed to reach the highest back steel temperature of $210^{\circ} \mathrm{C}$ while coating FG07 and FG08 with 6.0 and 7.0 grams of fiberglass recorded the lowest temperature $155^{\circ} \mathrm{C}$ and $150^{\circ} \mathrm{C}$ after 60 minutes exposure. Initially the temperature of FG07 and FG08 gradually increased from $10-18$ minutes. It reached to $290^{\circ} \mathrm{C}$ after 18 minutes fire test and after the formation of carboneous char the temperature is gradually decreased. It can be concluded that the use of fiberglass in the intumescent coating formulations helps to increase the thermal insulation properties of the coating, prolong the lifetime of steel structures and improved the strength of the char.

\section{Scanning Electron Microscopy (SEM) Analysis}

The SEM micrograph images of chars for outer and inner surface for sample FG07 
and FG08 burnt at $450{ }^{\circ} \mathrm{C}$ and $650^{\circ} \mathrm{C}$ were obtained using magnifications of $50 \mathrm{x}$ and 500x (outer surface) and 100x and 500x (inner surface).

\section{Fire test at $4500^{\circ} \mathrm{C}$}

There were bubbles, holes and cracks observed on the outer charring layer of sample FG07. The outer layer was smooth and demonstrates a good intumescent behavior. Bubbles are formed due to emission of $\mathrm{N}_{2}$ and ammonia gases during burning process. Inside the coating occurs the emission of $\mathrm{N}_{2}, \mathrm{NH}_{3}$ and $\mathrm{CO}_{2}$ gas and dehydration of water [3, 13]. The graphite flakes appear in the inner surface and produce the heat barrier to protect the steel (substrate). Small holes observed are due to the heat dissipation that occurs which prevent heat from transferring to the surface. Fig. 5 shows the inner surface of the coating using SEM.

Figure 6 shows the outer surface of the FG08 coating. The sample demonstrates a good intumescent behavior. The outer surface was smooth with bubbles, little cracks and folding structures. The formations of bubbles are due to the emission of $\mathrm{N}_{2}$ and ammonia gases during burning process. The FG08 coating and swells nicely since there are emissions of $\mathrm{N}_{2}, \mathrm{NH}_{3}$ and $\mathrm{CO}_{2}$ gas and dehydration of water which occurred inside the charring layer. Graphite flakes appeared in the inner surface as in and produce the heat barrier to protect the steel substrate.

\section{Fire Test at $650{ }^{\circ} \mathrm{C}$}

The SEM micrographs of chars for sample FG07 burnt at $650^{\circ} \mathrm{C}$ shows formation of large holes and white powder on the outer surface with cracks in the inner surface of the charring layer. The presence of white powder (ashes) as in Fig. 7 on the surface was the result of high burning temperature of $650{ }^{\circ} \mathrm{C}$ of the coatings which turned little portions of the coating into ashes. The surface of the coating swells properly due to dehydration of water and emission of gas from the holes. Large holes dissipated heat from inside and prevent the heat from transferring to the surface.

The SEM micrograph of chars for outer and inner surface for sample FG08 as in Fig. 8 shows the formation of holes, folding structure and white powder on the charring layer. The outer surface of the coating was smooth with small holes and the presence of white powder (ashes) due to high temperature of the fire test at $650{ }^{\circ} \mathrm{C}$. Inside the coating occurs the emission of $\mathrm{N}_{2}, \mathrm{NH}_{3}$ and $\mathrm{CO}_{2}$ gas and dehydration of water [13]. The graphite flakes appear in the inner surface and produce the heat barrier to protect the steel substrate. Small holes can be observed too where the heat dissipated from and prevent the heat from transferring to the surface.

\section{X-Ray Diffraction (XRD) Analysis}

XRD analysis is carried out to investigate the residual char composition of the intumescent coating after fire test at $450^{\circ} \mathrm{C}$. After the residue char of the intumescent coating was oxidized at high temperature, only some amorphous carbon and inorganic materials remained [13]. The inorganic materials might be the main protecting layer at later stages of burning. The facial residue of sample FG07 and FG08 were analyzed using XRD technique.

Figures 9-10 showed the XRD peaks of the facial residue char of sample FG07 and FG08 burnt at $450^{\circ} \mathrm{C}$. Several XRD peaks of the residue char at 5.929, 3.61734, $3.38003,3.18150,2.95135$ and 2.23516 were assigned according to JCPDS card. 
The peak at 5.929 was assigned to boron oxide. The peak at 3.65237 assigned to boron phosphate and at 3.3803 assigned to graphite. The major peak at 3.15807 assigned to sassolite and 2.16149 were assigned to boron phosphate oxide. The dehydration of boric acid yield boron oxide while the reaction between APP and boron oxide yield some boron phosphate in the charring element. The formation of sassolite (mineral acid of boric acid $\mathrm{H}_{3} \mathrm{BO}_{3}$ ) that has been shown due to the dehydration to support the formation of $\mathrm{B}_{2} \mathrm{O}_{3}$, glass-like material which increase fire retardancy of char $[4,13]$.

\section{Thermogravimetric Analysis (TGA)}

The thermogravimetric analysis of samples carried out under controlled air and temperature conditions gives an overview of the degradation process of the coating. The weight is plotted against the temperature to see if effective intumescent occurs. The aim is to obtain a high level of homogenous char at the end of the experiment with high amount of residue. This residue will limit the heat transfer to the substrate and will limit the gases feeding combustion process. A slow degradation rate will lead to a more homogenous char.

Figures 11-12 show the TG curves of sample FG07 and FG08 carried out at $10^{\circ} \mathrm{C} / \mathrm{min}$ under $\mathrm{N}_{2}$ over the whole range of temperature of $50^{\circ} \mathrm{C}-800^{\circ} \mathrm{C}$. There should be high amount of residue left at temperature higher than $800^{\circ} \mathrm{C}$ in order for the coatings to effectively protect the steel [14]. Some residues were observed after degradation over $800^{\circ} \mathrm{C}$. Sample FG08 with 7.0 grams of fiberglass left $28 \mathrm{wt} \%$ and FG07 with 6.0 grams of fiberglass left $24 \mathrm{wt} \%$ residues at $800^{\circ} \mathrm{C}$ temperature than. It means that FGO8 have 16 percent higher residual weight compared to FG07. The residual weight increased due to increased the weight percentage of fiberglass. The former gave enough charring to allow a good expansion shown in fire test.

\section{CONCLUSIONS}

This study was focused into the preparation of the expandable graphite as char former and fiberglass as an insulating reinforcement in enhancing the thermal insulation property of the coating. Various amount of fiberglass ranging from 1.0-7.0 grams were added into the basic intumescent coating formulations. Sample FG08 and FG07 with 7.0 grams and 6.0 grams of fiberglass recorded the best results in terms of the enhanced thermal insulation properties of the coatings. The FG08 and FG07 coating recorded the best expansion during fire test at $450{ }^{\circ} \mathrm{C}$ and $650^{\circ} \mathrm{C}$ with 5-7 times expansion than the original thickness of the coating, the lowest back steel temperature which were much less than $220^{\circ} \mathrm{C}$ during the an-hour thermal insulation test and illustrated good coating characteristics after analysis using SEM. These coatings also recorded the presence of graphite, boron oxide and boron phosphate after XRD testing and with good residue left after degradation analysis using SEM. The residual weight increased due to increase the weight percentage of fiberglass in the intumescent coating. Thus, it can be concluded that the addition of fiberglass into the basic intumescent formulations helps to enhance the thermal characteristic of the coating and assists to maintain the base materials for longer time. 


\section{ACKNOWLEDGMENT}

The authors acknowledge the assistance and the support received from the Mechanical Engineering Department of Universiti Teknologi PETRONAS, Malaysia.

\section{REFERENCES}

[1] Jimenez, M., Duquesne. S, Bourbigot. S,. "Multiscale Experimental Approach for Developing High-Performance Intumescent Coatings", Industrial \& Engineering Chemistry Research 45 (13): pp 4500- 4508 (2006).

[2] Gu, Jun-wei, Zhang. Guang-cheng, Dong. Shan-lai, Zhang. Qiu-yu, Kong. Jie. "Study on Preparation and Fire-Retardant Mechanism Analysis of Intumescent Flame-retardant Coatings"._Surface and Coatings Technology 201: 7835-7841, (2007).

[3] Jimenez, M., S. Duquesne, and S. Bourbigot. "Intumescent Fire Protective Coating: Toward a Better Understanding of their Mechanism of Action". Thermochimica Acta 449(1-2): pp16-26 (2006).

[4] Jiminez, M., Duquesne. S, Bourbigot. S. "Characterization of the Performance of an Intumescent Fire Protective Coating". Surface and Coatings Technology 201(3-4):pp 979 - 987, (2006).

[5] Guoxin, Li, Junfen. Yang, Tingshu. He, Yonghua. Wu, Guozheng. Liang. "An Investigation of the Thermal Degradation of the Intumescent Coating Containing $\mathrm{MoO}_{3}$ and $\mathrm{Fe}_{2} \mathrm{O}_{3}$ ". Surface and Coatings Technology 202(13): pp. 3121-3128, (2008).

[6] Wang, Z., E. Han and Wei Ke. "Influence of expandable graphite on fire resistance and water resistance of flame-retardant coatings." Corrosion Science, 49(5): 2237-2253, (2007).

[7] Przybylak-Wladyka, M., Kozlowski. M. "Thermal Characteristic of Different Intumescent Coatings". Fire and Materials, 23(1): pp33-43 (1999).

[8] Bugajni, M., Le Bras. M, Bourbigot. S, "New Approach to the dynamic Properties of an Intumescent Materials", Fire and Materials 23(1): pp 49-51, (1999).

[9] Xiling, C., Song K., Li J., Liu J. "Preparation of lower-sulfur content and expandable graphite." Carbon 34(12): pp1599-1600, (1996).

[10] Hao, J., Chow W.K. "A Brief Review of Intumescent Fire Retardant Coatings", 46: pp. 300-440, (2003).

[11] Ullah, S., Ahmed F. and P.S.M. Megat-Yusoff. "Effect of Boric Acid with Kaolin Clay on Thermal Degradation of Intumescent Fire Retardant Coating" 11(21): pp 3645-3649, (2011).

[12] Amir, N., Ahmad F. and Megat-Yusoff, P.S.M., 2011, Study on the Fibre Reinforced Epoxy-Based Intumescent Coating Formulations and their Char Characteristics, 11(10): pp1678-1687, (2011).

[13] Ullah, S., Ahmed F. and P. S. M. Megat Yusoff. "The effect on Expansion and Thermal degradation of $63 \mu \mathrm{m}$ Expandable graphite on Intumescent fire retardant coating composition". 15(2): pp 944-951 (2011).

[14] Amir, N., Ahmad F. and Megat-Yusoff, P.S.M. "Characterization of Inorganic Non-Metallic Fibre Reinforced Epoxy-Based Intumescent Coatings (FRIC) and Chartex Journal of applied sciences7 (2): pp. 143-151, (2011). 
Table 1: Formulations of intumescent coating (in grams)

\begin{tabular}{|c|c|c|c|c|c|c|c|}
\hline No & EG & APP & MEL & BA & Epoxy & Hardener & FG \\
\hline FG01 & 5.5 & 11.1 & 5.5 & 11.5 & 44.60 & 22.20 & 0 \\
\hline FG02 & 5.5 & 11.1 & 5.5 & 11.5 & 42.76 & 21.38 & 1 \\
\hline FG03 & 5.5 & 11.1 & 5.5 & 11.5 & 42.10 & 21.00 & 2 \\
\hline FG04 & 5.5 & 11.1 & 5.5 & 11.5 & 41.42 & 20.71 & 3 \\
\hline FG05 & 5.5 & 11.1 & 5.5 & 11.5 & 40.76 & 20.38 & 4 \\
\hline FG06 & 5.5 & 11.1 & 5.5 & 11.5 & 40.1 & 20.00 & 5 \\
\hline FG07 & 5.5 & 11.1 & 5.50 & 11.5 & 39.4 & 19.71 & 6 \\
\hline FG08 & 5.5 & 11.1 & 5.5 & 11.5 & 39.10 & 19.00 & 7 \\
\hline
\end{tabular}

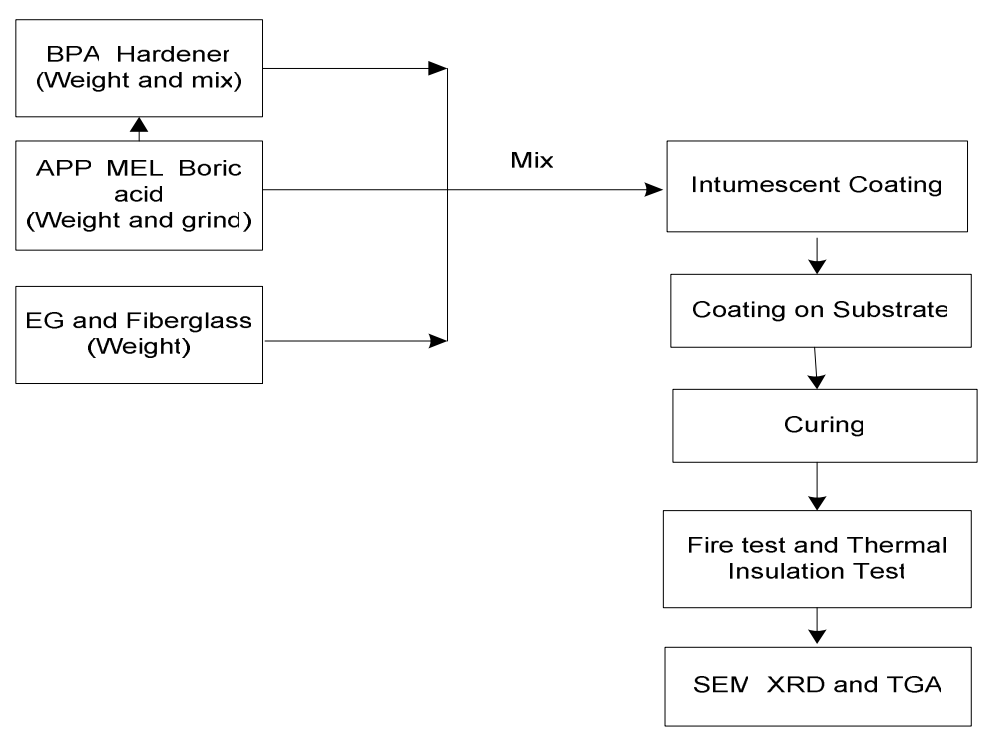

Fig. 1. Experimental flow chart.

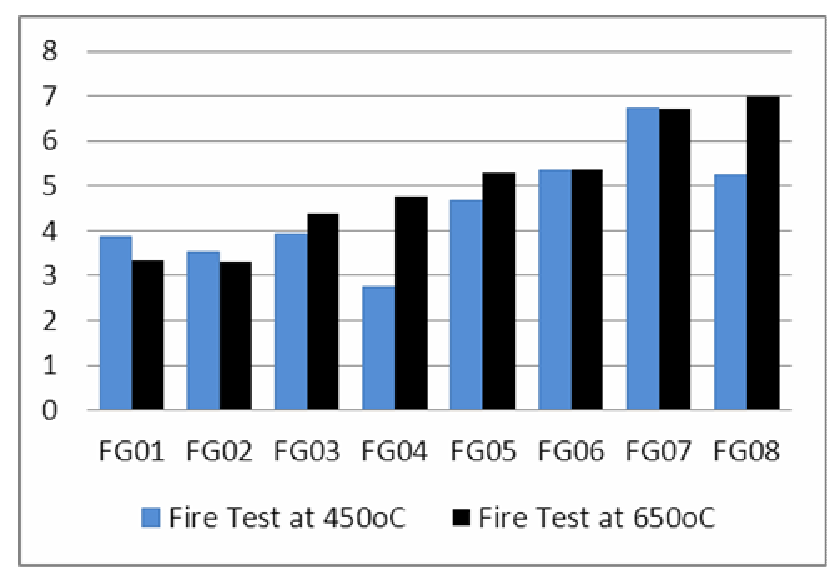

Fig. 2. Expansion ratio of coating burnt at $450^{\circ} \mathrm{C}$ and $650^{\circ} \mathrm{C}$. 

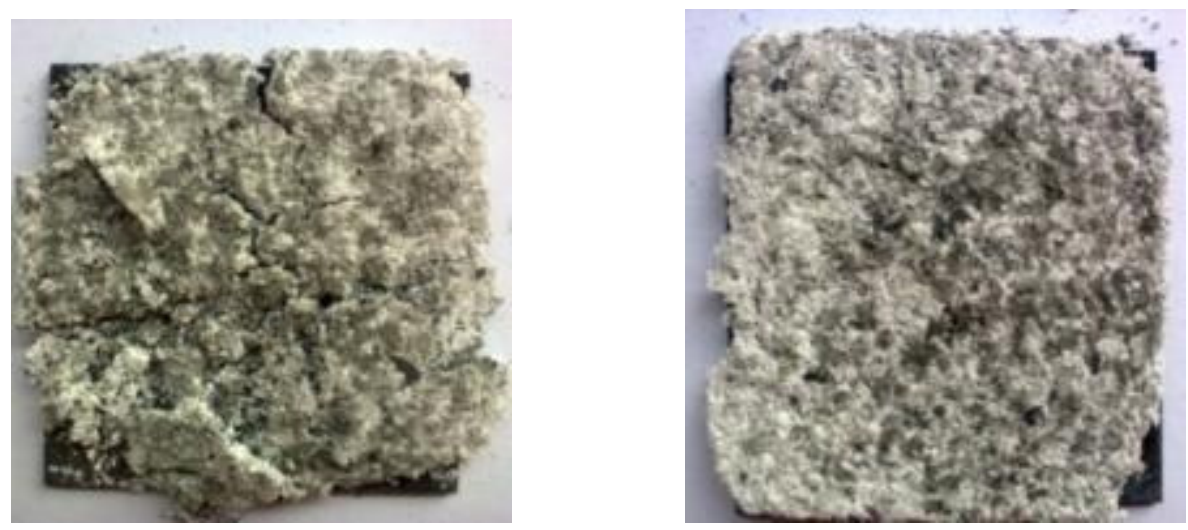

Fig. 3. After fire test at $850^{\circ} \mathrm{C}$.

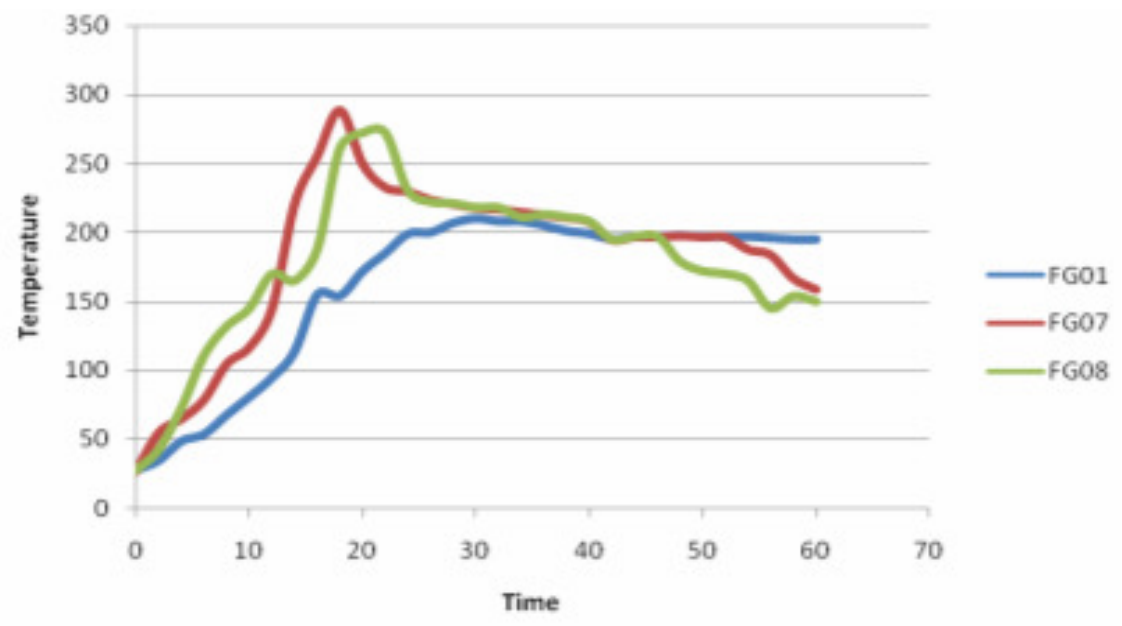

Fig. 4. Temperature versus Time.

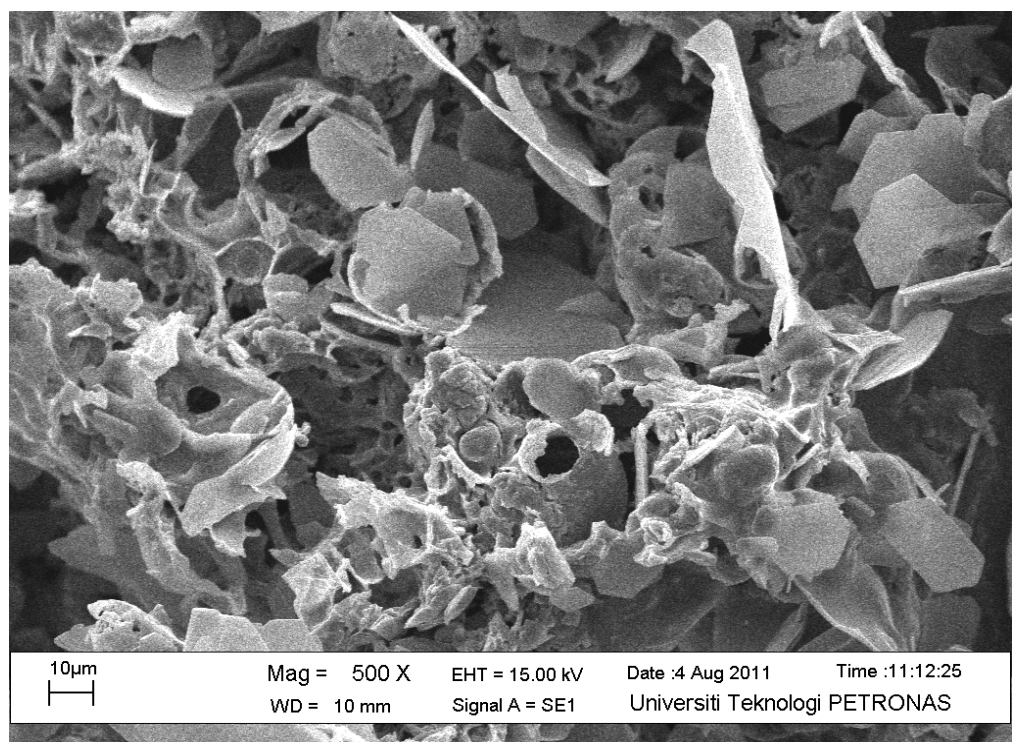

Fig. 5. SEM micrograph of FGO7 coating for inner surface: 500x. 


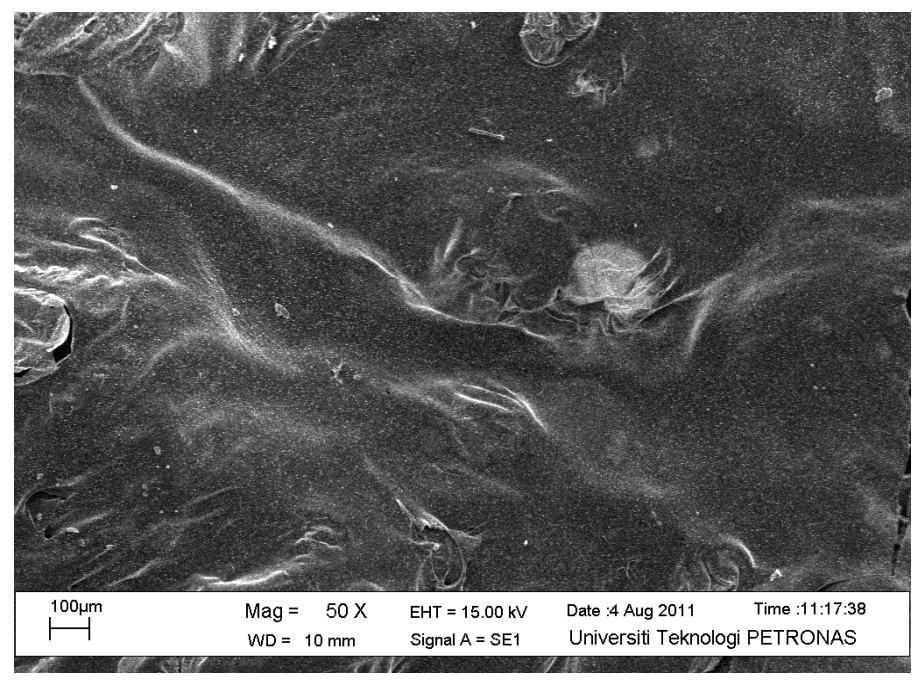

Fig. 6. SEM micrograph of FGO8 coating for outer surface: 50x.

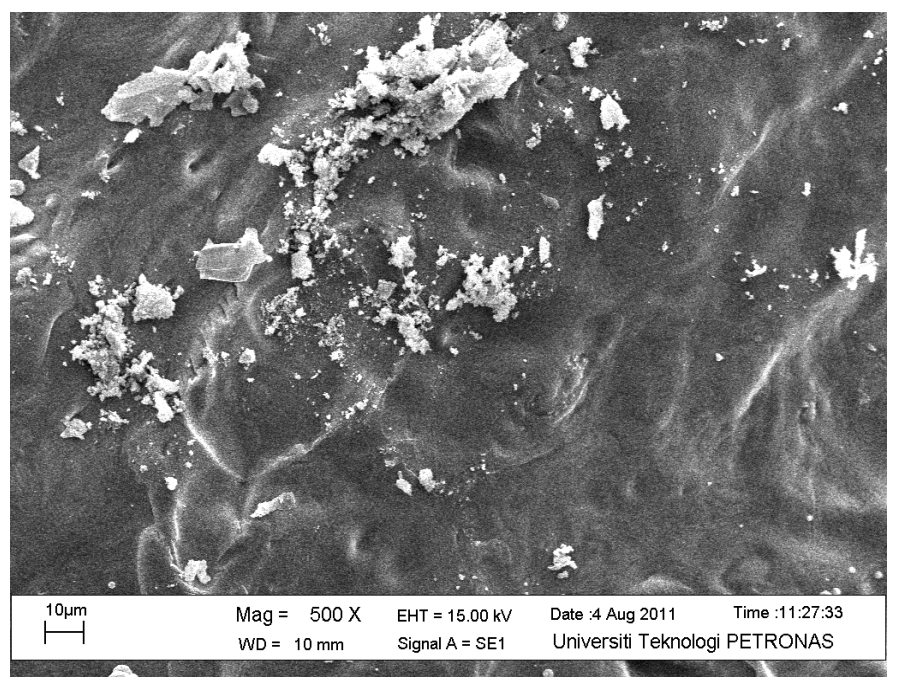

Fig. 7. SEM micrograph of FGO7 coating for outer surface: 500x.

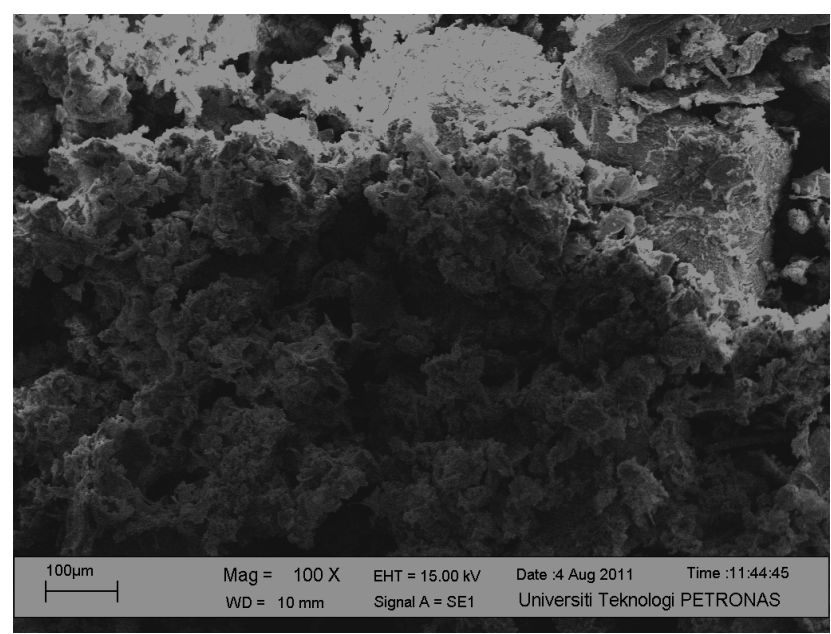

Fig. 8. SEM micrograph of FGO8 coating for inner surface: 100x. 


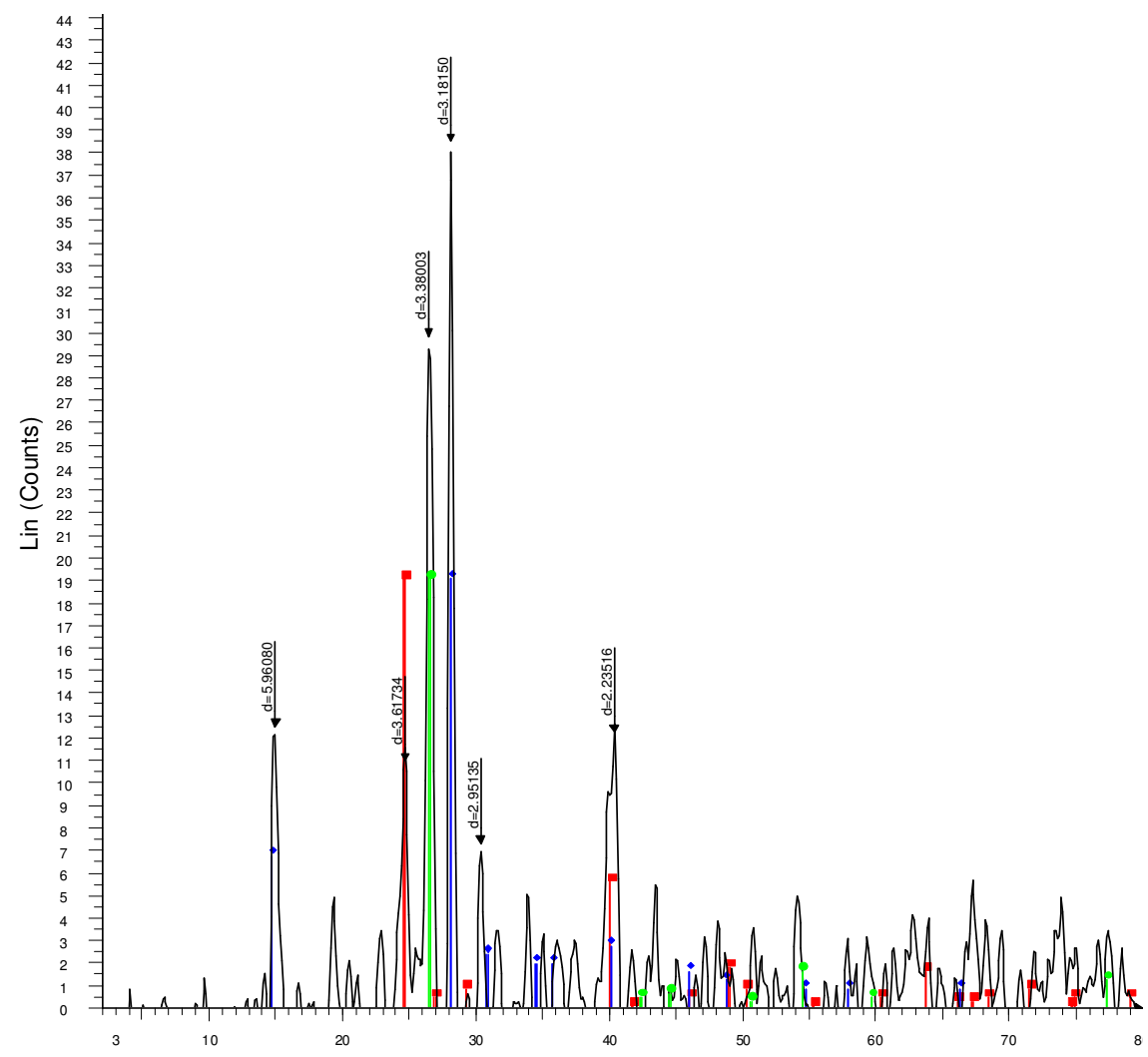

Fig. 9. XRD curve of the residue char of sample FG07 at $450 \stackrel{\circ}{\circ}$.

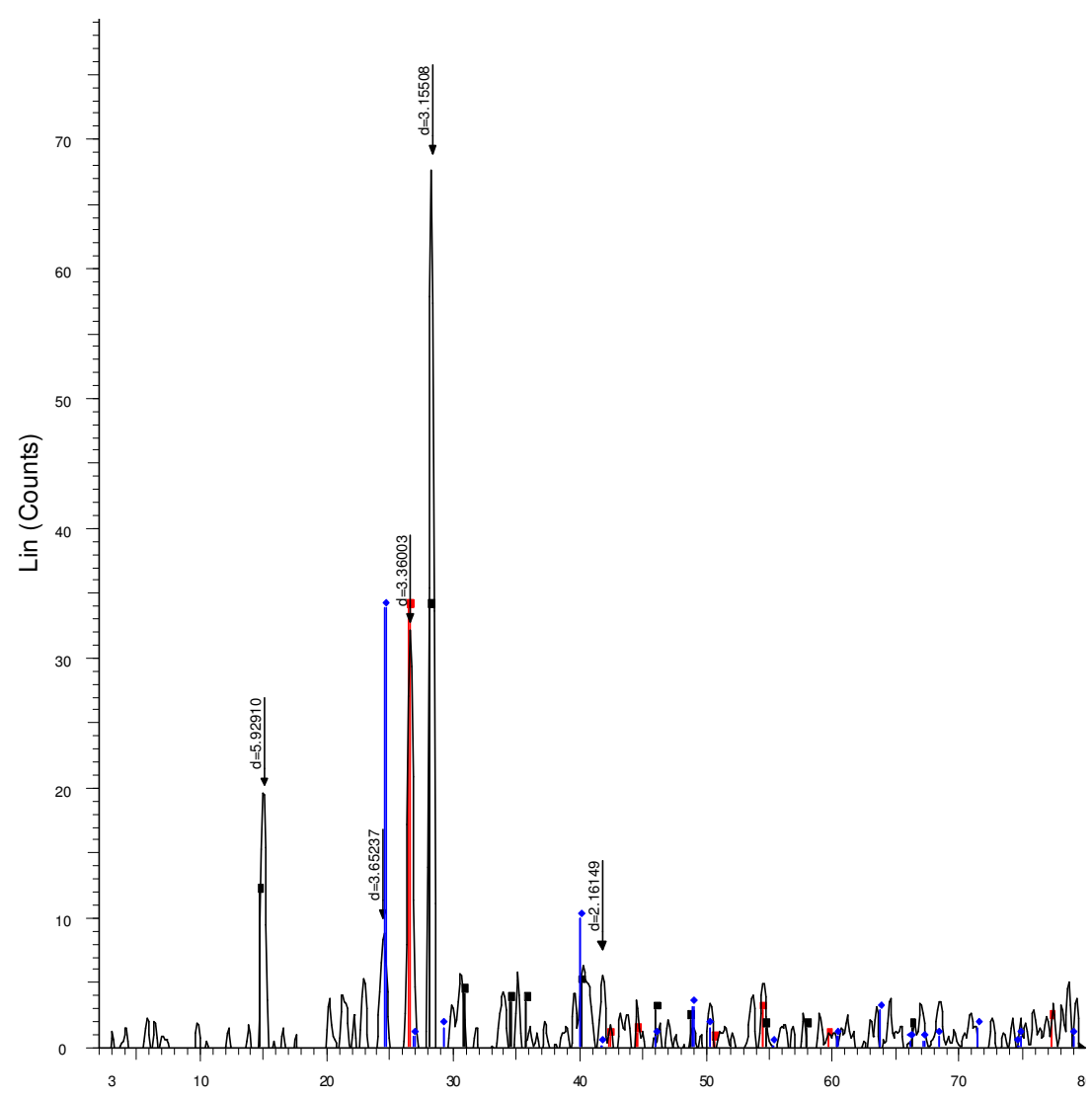

Fig. 10. XRD curve of residue char of sample FG08 at $450^{\circ} \mathrm{C}$. 


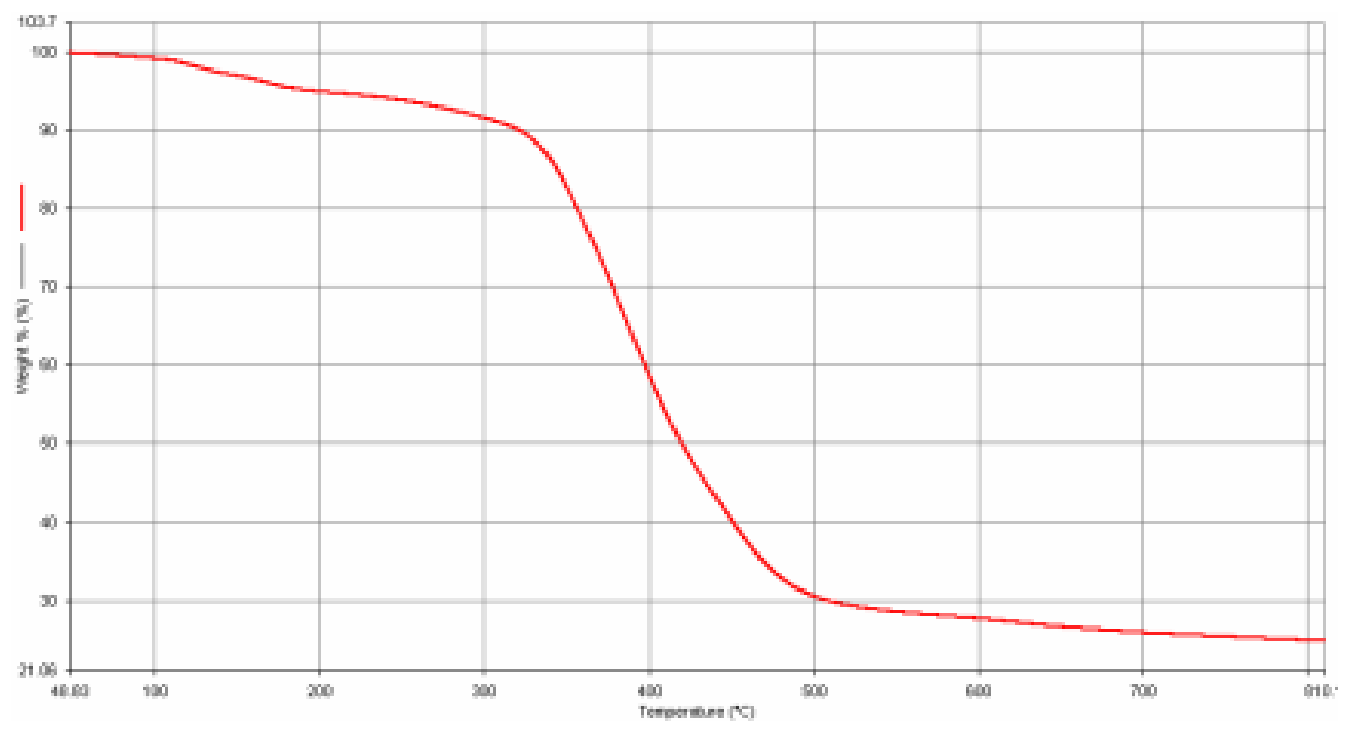

Fig. 11. TG curves of sample FG07.

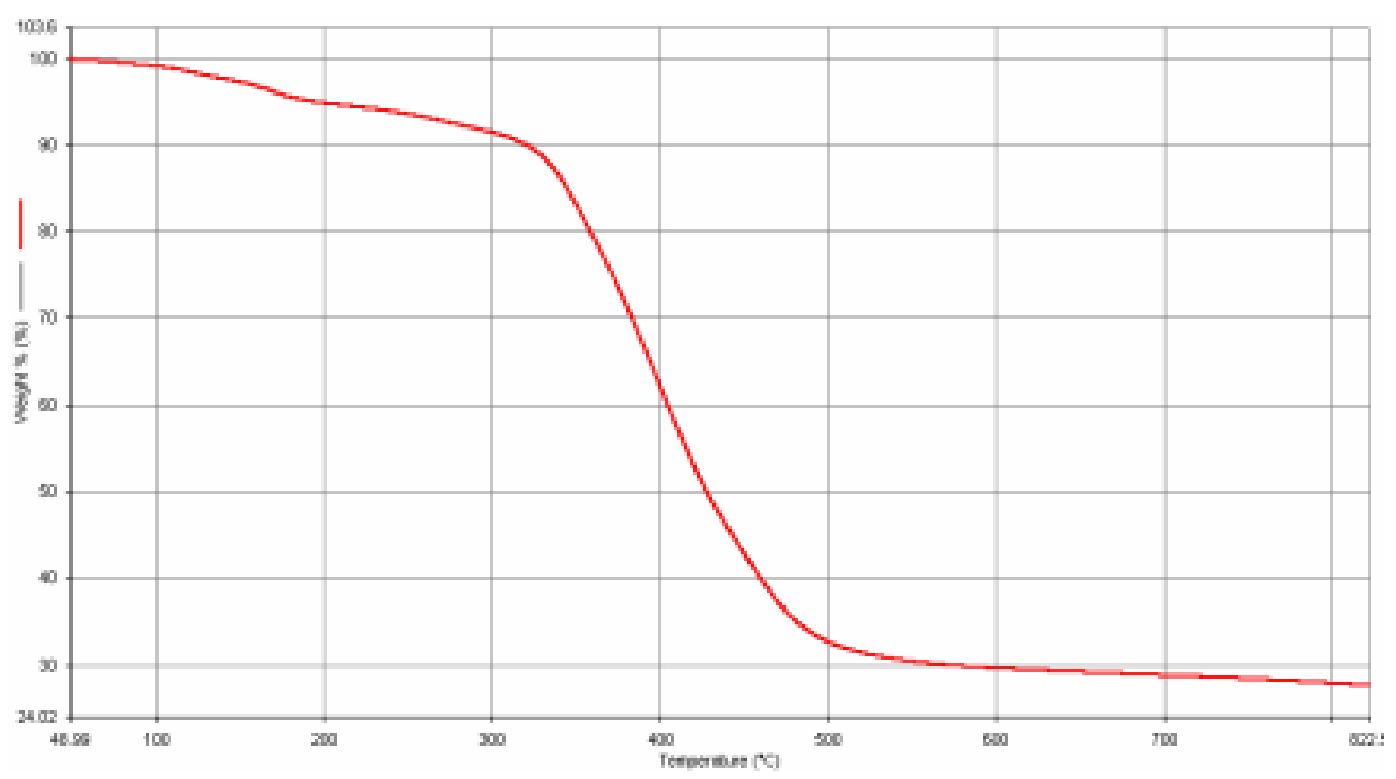

Fig. 12. TG curves of sample FG08. 